\title{
Ventilatory drive and ventilatory response during rebreathing
}

\author{
NANTA MARANETRA and M. C. F. PAIN \\ Respiratory Unit and University of Melbourne Department of Medicine, Royal Melbourne Hospital, \\ Melbourne, Australia
}

\begin{abstract}
Maranetra, N. and Pain, M. C. F. (1974). Thorax, 29, 578-581. Ventilatory drive and ventilatory response during rebreathing. The increase in inspiratory airway pressure generated against a transiently occluded airway during rebreathing is proposed as a simple index of ventilatory drive $\left(\Delta \mathrm{P} / \Delta \mathrm{PCO}_{2}\right)$. A study of this index in 12 normal subjects and 50 patients with chronic airways obstruction demonstrated no significant difference between normals and patients in $\Delta \mathrm{P} / \Delta \mathrm{PCO}_{2}$ despite an overall reduction in the ventilatory response to carbon dioxide $\left(\Delta \mathrm{VE} / \Delta \mathrm{PCO}_{2}\right)$ in the patients. A significant association was demonstrated between the ventilatory response to carbon dioxide, $\Delta \mathrm{P} / \Delta \mathrm{PCO}_{2}$ and the degree of airways obstruction. Patients with a low $\Delta \mathrm{P} / \Delta \mathrm{PCO}_{2}$ showed greater hypoxaemia, hypercapnia, and polycythaemia than patients with a higher $\Delta \mathrm{P} / \Delta \mathrm{PCO}_{2}$ for the same degree of airways obstruction.
\end{abstract}

The increase in minute ventilation that occurs during rebreathing has been expressed as the ventilatory response to carbon dioxide $\left(\Delta \dot{\mathrm{V}} \mathrm{E} / \Delta \mathrm{PCO}_{2}\right)$ and used as an index of respiratory centre sensitivity. This implies that the output from the stimulated 'respiratory centre' is faithfully reflected by the output from the ventilatory apparatus. While this may be reasonable in subjects with normal mechanical loading of the respiratory muscles, it is probably erroneous in patients with abnormal ventilatory mechanics, and this has prompted a search for a more appropriate means of assessing the output from the respiratory centre during carbon dioxide stimulation. Thus increases in transpulmonary pressure (O'Donnell and Hood, 1971) and diaphragmatic electrical activity (Lourenco and Miranda, 1968) have been studied to define the rate of increase in respiratory muscle work in response to rebreathing. These techniques are not simple and not very comfortable for the subject so that data from repeated measurements become difficult to obtain.

We have attempted to measure the increase in airway pressure generated during inspiration against a momentarily closed airway during rebreathing in normal subjects and patients with chronic airflow obstruction and used this index as an expression of ventilatory drive.

\section{SUBJECTS AND METHODS}

Two groups were studied. Twelve normals, whose ages ranged from 18 to 36 years, were medical and technicalo staff of the hospital.

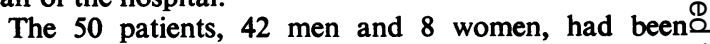
referred to the laboratory for assessment of airways $\overrightarrow{\vec{\circ}}$ obstruction. Their ages ranged from 41 to 73 years. $\exists$ Their pulmonary functional status is shown in Table $I$. Measurements of forced expired volume in one second $\left(\mathrm{FEV}_{1.0}\right)$, fractional carbon monoxide uptake, and arterial blood and expired gases were performed using standard techniques.

T A B L E I

CLINICAL AND FUNCTIONAL STATUS OF 50 PATIENTS WITH AIRWAYS OBSTRUCTION

\begin{tabular}{|c|c|c|c|}
\hline Study & Mean & SD & 윽 \\
\hline $\begin{array}{l}\text { FEV }_{1.0}(\% \text { predicted) } \\
\text { Fractional CO uptake (\%) } \\
\text { Bronchodilator responsiveness (\%) } \\
\text { PaO }_{2} \text { (mmHg) } \\
\mathrm{PaCO}_{2}(\mathrm{mmHg}) \\
\mathrm{Haematocrit}(\%) \\
\text { RVH ECG score } \\
\text { Right heart failure }\end{array}$ & $\begin{array}{c}37 \\
31 \\
23 \\
70 \\
43 \\
49 \\
2 \cdot 5 \\
20 / 50\end{array}$ & $\begin{array}{r}14 \\
6 \\
12 \\
14 \\
10 \\
7 \\
2\end{array}$ & $\begin{array}{l}\text { D } \\
\text { OD. } \\
\text { N } \\
\text { O } \\
\text { N } \\
\text { N }\end{array}$ \\
\hline
\end{tabular}

1RVH ECG score refers to the sum of abnormalities noted on the basis of: $P$ pulmonale $=1$; right $Q R S$ axis deviation $=1$; clockwiso rotation $=1$; dominant $R$ wave in $V 4 R$ or $V 1=2 ; S T-T$ depression ip V1-3=2.

The rebreathing circuit is shown in Fig. 1 and is basicalli that used by Read (1967). At the end of normal expiration the patient is connected to a 7 litre bag containing about $7 \%$ carbon dioxide in oxygen. Ventilation during a 4-minute rebreathing period is recorded with a water 8 filled spirometer and kymograph, and the carbon dioxide tension is continuously monitored using an infrared 


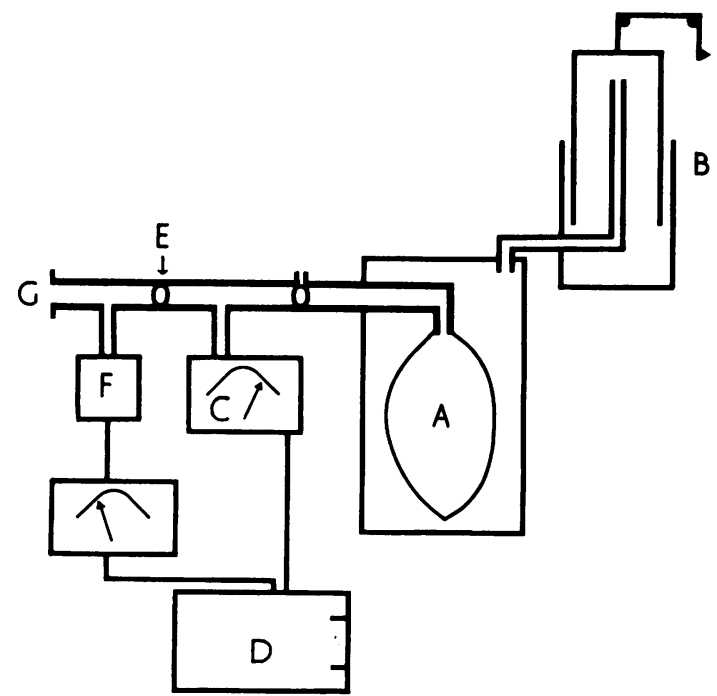

FIG. 1. The rebreathing circuit. A, rebreathing bag; $\mathrm{B}$, spirometer and kymograph; $\mathrm{C}, \mathrm{CO}_{2}$ analyser; D, recorder; $\mathrm{E}$, manually operated interrupter tap; $\mathrm{F}$, pressure transducer; G, mouthpiece.

rapid $\mathrm{CO}_{2}$ Analyser (Godart Capnograph). At 30 second intervals during rebreathing a tap is turned by hand at the beginning of inspiration and the subject attempts to inspire against an occluded airway. The period of occlusion begins within $200 \mathrm{msec}$ of the start of inspiration and the period of occlusion is about $600 \mathrm{msec}$. The inspiratory pressure so generated is monitored using a pressure transducer (1280 c Hewlett-Packard) and amplifier (Sanborn 350-1100 c), and displayed with the Capnograph signal on a two-channel Sanborn recorder (Fig. 2). The

\section{Ventilation}
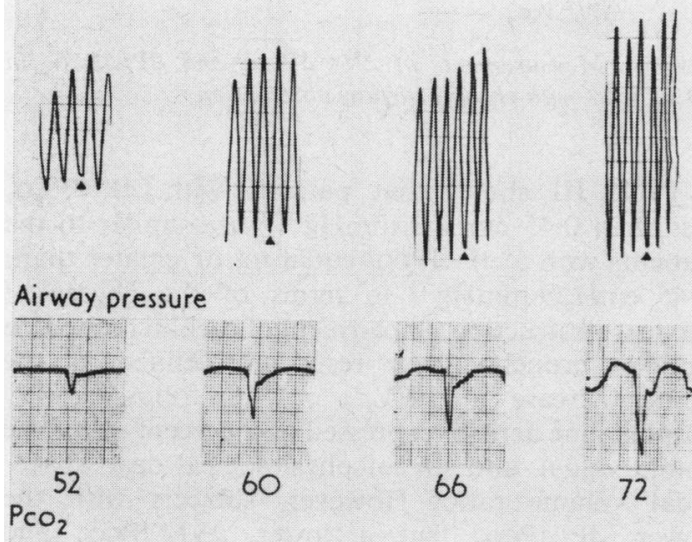

72

FIG. 2. Example of changes in ventilation and airway pressure measured during rebreathing in a normal subject. slope of the line of best fit between $\dot{\mathrm{V}}$ and $\mathrm{PCO}_{2}$ $\left(\Delta \dot{\mathrm{V}} / \Delta \mathrm{PCO}_{2}\right)$ is expressed as the ventilatory response (litre $\mathrm{min}^{-1} \mathrm{mmHg}^{-1}$ ) and similarly that between the inspiratory airway pressure against the occluded airway and $\mathrm{PCO}_{2}\left(\Delta \mathrm{P} / \Delta \mathrm{PCO}_{2}\right)$ is termed the ventilatory drive ( $\mathrm{cm} \mathrm{H}_{2} \mathrm{O} \mathrm{mmHg}^{-1}$ ).

\section{RESULTS}

NORMAL SUBJECTS The ventilatory response ranged from 0.7 to 4.7 litre min $^{-1} \mathrm{mmHg}^{-1}$ (mean 1.9; $\mathrm{SD} \pm 1.0$ ), and the ventilatory drive was 0.2 to $2.4 \mathrm{~cm}$ $\mathrm{H}_{2} \mathrm{O} \mathrm{mmHg}^{-1}$ (mean $0.95 ; \mathrm{SD} \pm 0.5$ ). There was a significant correlation between the two $(r=0.6$; $\mathbf{P}<0.001$ ).

PATIENTS The ventilatory response was $0 \cdot 1$ to $2 \cdot 7$ litre $\mathrm{min}^{-1} \mathrm{mmHg}^{-1}$ (mean $0.73 ; \mathrm{SD} \pm 0.5$ ) and the ventilatory drive was 0.1 to $2.5 \mathrm{~cm} \mathrm{H}_{2} \mathrm{O} \mathrm{mmHg}^{-1}$ (mean 0.88; $\mathrm{SD} \pm 0.7$ ). Again the correlation between drive and response was significant $(r=0.71$; $P<0.001)$. The results are summarized in Table II.

T A B L E I I

$\Delta \mathrm{P} / \Delta \mathrm{PCO}_{2}$ AND $\Delta \dot{\mathrm{V} E} / \Delta \mathrm{PCO}_{2}$ VALUES $(\mathrm{MEAN} \pm \mathrm{SD})$ IN 12 NORMALS AND 50 PATIENTS

\begin{tabular}{l|c|c|c}
\hline & Normal & Obstructed & \\
\hline$\Delta \mathrm{P} / \Delta \mathrm{PCO}_{2}$ & $0.95 \pm 0.5$ & $0.88 \pm 0.74$ & $\begin{array}{c}\mathrm{NS} \\
t=5.4 \\
\Delta \mathrm{VE} / \Delta \mathrm{PCO}_{2}\end{array}$ \\
& $1.9 \pm 1.0$ & $0.73 \pm 0.55$ & $\mathbf{P}<0.001$ \\
\hline
\end{tabular}

\section{DISCUSSION}

The increase in ventilation that normally occurs during rebreathing is associated with increases in inspiratory work (Milic-Emili and Tyler, 1963). Transpulmonary pressure differences between inspiration and expiration will increase, resulting in a certain increase in tidal volume (depending on the static compliance and flow resistive properties of the lungs), and the pressure generated during attempted inspiration against a transiently occluded airway would seem intuitively to represent some function of the drive to the ventilatory apparatus. There are a number of factors which might mitigate against the ready acceptance of $\Delta \mathrm{P} / \Delta \mathrm{PCO}_{2}$ measured by this technique as a simple index of ventilatory drive. Thus, ventilation increases due to an increase in rate without change in tidal volume would result in a lower $\Delta \mathrm{P} / \Delta \mathrm{PCO}_{2}$ in subjects without frequency dependence of compliance. The use of the absolute increase in airway pressure over the rebreathing period overlooks the difference in volume expansion produced in lungs with differences in static pressurevolume curves, and the exact onset and duration of each interruption and attempted inspiration may well 
determine the extent of the pressure generated. While these factors require further examination in patients in whom more detailed information concerning pulmonary mechanical properties is available, the following points can be made.

The pattern of ventilation increase in both normals and subjects with airflow obstruction is invariably one of an increase in both rate and tidal volume. In a few patients we made simultaneous measurements of transpulmonary pressure increases and interrupted airway pressure increases during rebreathing and these measurements showed a highly significant linear correlation $(r=0.87, n=10)$ with a slope of 0.73 (unpublished observations).

Manual tap operation may induce differences in the time of onset of interruption and differences in the duration of interruption. Studies on sudden airways occlusion in cats (Whitelaw and Milic-Emili, 1973) would suggest that reflex inhibition of inspiratory effort is absent with occlusion occurring within the first $250 \mathrm{msec}$ of inspiration, and that duration of occlusion is of minor importance. We were able, with practice, to achieve interruption within an average of $150 \mathrm{ml}$ of the start of inspiration and this is equivalent to an average onset of interruption of $150 \mathrm{msec}$ from the start of inspiration. Studies designed to demonstrate the influence of interruption at different volumes above functional residual capacity showed that there was little change in the generated pressure $( \pm 20 \%)$ provided the interruption occurred within $200 \mathrm{ml}$ of the start of inspiration. Because of concern about possible cortical inhibition influencing the pressure generated during attempted inspiration against the occluded tap, the rate of change in pressure was also calculated. It was found that this index $\left[(\mathrm{dp} / \mathrm{dt}) / \Delta \mathrm{PCO}_{2}\right]$ appeared to have no advantage over $\Delta \mathrm{P} / \Delta \mathrm{PCO}_{2}$ and the two were highly significantly related.

Obviously considerable technical improvement would be achieved by making the interruption procedure an electronically activated one by which means the onset and duration of interruption can be precisely controlled.

As expected, the wide normal range of $\Delta \dot{\mathrm{V}} \mathrm{E} / \Delta \mathrm{PCO}_{2}$ found by other workers (Read, 1967; Rebuck and Read, 1971) was again demonstrated in this study and was significantly associated with a range of $\Delta \mathrm{P} / \Delta \mathrm{PCO}_{2}$. Although our normals are a younger group than the patients, and direct comparison is not strictly possible, the mechanical load imposed by airways obstruction reduces the output $\left(\Delta \dot{\mathrm{VE}} / \Delta \mathrm{PCO}_{2}\right)$ by an average of $60 \%$, and the individual ventilatory response is associated with the drive $\left(\Delta \mathrm{P} / \Delta \mathrm{PCO}_{2}\right)$ and the extent of airways obstruction according to the following equation:

$$
\begin{gathered}
\Delta \dot{\mathrm{VE}} / \Delta \mathrm{PCO}_{2}=0.5 \Delta \mathrm{P} / \Delta \mathrm{PCO}_{2}+ \\
0.01 \mathrm{FEV}_{1.0} \% \mathrm{~N}-0.09 \\
\mathrm{n}=50 \quad \mathrm{R}=0.76
\end{gathered}
$$

where $\mathrm{FEV}_{1.0} \% \mathrm{~N}$ is the one second forced expiratory volume expressed as a percentage of predicted normal.

The value for $\Delta \mathrm{P} / \Delta \mathrm{PCO}_{2}$ among the subjects with $\overrightarrow{\vec{\omega}}$ airways obstruction was not significantly different $\stackrel{\omega}{\circ}$ from that of the normals despite a difference in $\vec{x}$ $\Delta \dot{\mathrm{VE}} / \Delta \mathrm{PCO}_{2}$, suggesting that the development of airways obstruction does not necessarily lead to a reduction of drive. This agrees with the findings of $i$ O'Donnell and Hood (1971), who showed similar $\infty$ preservation of $\Delta$ transpulmonary pressure $/ \Delta \mathbf{P C O}_{2}$ 을 relationships with very low $\Delta \dot{\mathrm{V}} / \Delta \mathrm{PCO}_{2}$ in patients with hypercapnic airways obstruction.

Figure 3 illustrates that while the overall correlation between drive and response was significant, some individual patients had a higher than normal drive whereas others had a lower than normal drive for the same ventilatory response.

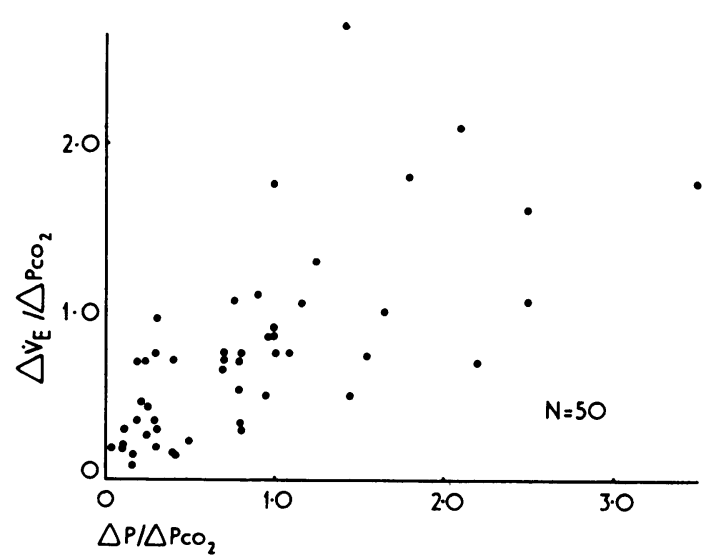

FIG. 3. Measurements of $\Delta \dot{\mathrm{V}} / \Delta \mathrm{PCO}_{2}$ and $\Delta \mathrm{P} / \Delta \mathrm{PCO}_{2}$ in $\mathrm{\circ}$ 50 subjects with chronic airflow obstruction.

Table III shows that patients with $\Delta \mathrm{P} / \Delta \mathrm{PCO}_{2}$ o less than $0.45 \mathrm{cmH}_{2} \mathrm{O} \mathrm{mmHg}{ }^{-1}$ were similar to the $\mathrm{O}$ patients with a $\Delta \mathrm{P} / \Delta \mathrm{PCO}_{2}$ equal to, or greater than, $0.45 \mathrm{cmH}_{2} \mathrm{O} \mathrm{mmHg} \mathrm{mm}^{-1}$ in terms of the degree of 0 airways obstruction, impairment of carbon monoxide uptake, bronchodilator response (defined as the $\frac{\mathscr{\Phi}}{\Phi}$ acute increase in $\mathrm{FEV}_{1.0}$ or $\mathrm{VC}$ following $1 \% \stackrel{9}{\rightarrow}$ isoprenaline aerosol expressed as a percentage of the $\square$ initial value), and size of physiological dead space/ tidal volume ratio. However, subjects with the $\mathbb{\mathbb { D }}$ lower $\Delta \mathrm{P} / \Delta \mathrm{PCO}_{2}$ had a lower $\Delta \dot{\mathrm{VE}} / \Delta \mathrm{PCO}_{2}$ and $\mathbb{\mathbb { D }}$ arterial oxygen tension and higher arterial carbon dioxide tension, haematocrit, and incidence of 
T A B L E I I I

RELATIONSHIP BETWEEN 'VENTILATORY DRIVE' AND CLINICAL FEATURES

\begin{tabular}{|c|c|c|c|c|c|}
\hline & \multicolumn{2}{|c|}{$\begin{array}{c}\Delta \mathrm{P} / \Delta \mathrm{PCO}_{2}<0.45 \\
(\mathrm{~N}=19)\end{array}$} & \multicolumn{2}{|c|}{$\begin{array}{c}\Delta \mathrm{P} / \Delta \mathrm{PCO}_{2}= \\
0.45-1.45 \\
(\mathrm{~N}=22)\end{array}$} & \\
\hline & Mean & SD & Mean & SD & \\
\hline $\begin{array}{l}\mathrm{FEV}_{1.0} \% \\
\text { predicted } \\
\text { FCO \% } \\
\text { VD/VT } \\
\text { Bronchodilator } \\
\text { responsiveness } \\
(\%) \\
\text { Right heart failure } \\
\Delta \mathrm{VE}^{\circ} / \Delta \mathrm{PCO}_{2} \\
\mathrm{PaO}_{2} \\
\mathrm{PaCO}_{2} \\
\text { Haematocrit } \\
\text { RVH ECG score }\end{array}$ & $\begin{array}{l}32 \\
29 \\
0.4 \\
19 \\
19 \\
0 \cdot 3 \\
62 \\
51 \\
52 \\
3.4\end{array}$ & $\begin{array}{c}9 \\
9.2 \\
12 \\
9 \\
9 \\
2\end{array}$ & $\begin{array}{c}37 \\
31 \\
0.4 \\
\\
25 \\
0.8^{8} \\
72 \\
40 \\
46 \\
1.8\end{array}$ & $\begin{array}{l}12 \\
4 \\
0.07 \\
12 \\
12 \\
0.5 \\
14 \\
6 \\
5 \\
2\end{array}$ & $\begin{array}{c}\text { NS } \\
\text { NS } \\
\text { NS } \\
\\
\text { NS } \\
\text { NS } \\
P<0.001 \\
P=0.025 \\
P<0.001 \\
P=0.01 \\
P=0.025\end{array}$ \\
\hline
\end{tabular}

electrocardiographic abnormalities suggesting cor pulmonale.

The prognostic significance of a low $\Delta \mathrm{P} / \Delta \mathrm{PCO}_{2}$ in a normal subject who develops airways obstruction in terms of his clinical presentation, susceptibility to agents producing respiratory depression, and the development of polycythaemia and cor pulmonale is of some interest but present data do not yet allow any definite conclusions to be drawn.

We believe that this index, which is easily measured with no patient discomfort, is an expression of ventilatory drive as distinct from ventilatory response and as such is more relevant to the assessment of ventilatory control in patients with airways obstruction.
This work arose from a discussion with L. D. Pengelly at McMaster University, Hamilton, Ontario in 1971 concerning the immediate effects of mechanical loading during rebreathing (Journal of Applied Physiology, 30(1), 7 (1971)).

\section{REFERENCES}

Lourenco, R. V. and Miranda, J. M. (1968). Drive and performance of the ventilatory apparatus in chronic obstructive lung disease. New England Journal of Medicine, 279, 53.

Milic-Emili, J. and Tyler, J. M. (1963). Relation between work output of respiratory muscles and end-tidal $\mathrm{CO}_{2}$ tension. Journal of Applied Physiology, 18, 497.

O'Donnell, T. V. and Hood, L. J. (1971). Decreased chemoreceptor sensitivity and chronic obstructive lung disease. Journal of the Royal College of Physicians of London, 6, 53.

Read, D. J. C. (1967). A clinical method for assessing the ventilatory response to carbon dioxide. Australasian Annals of Medicine, 16, 20.

Rebuck, A. S. and Read, J. (1971). Patterns of ventilatory response to carbon dioxide during recovery from severe asthma. Clinical Science, 41, 13.

Whitelaw, W. A. and Milic-Emili, J. (1973). A new method for evaluating respiratory centre output. Physiologist, 16, 486.

Requests for reprints to: Dr. M. C. F. Pain, Respiratory Unit, Royal Melbourne Hospital, Melbourne, Australia, 3050. 